\title{
TESTE DE VIGOR NA AVALIAÇÃO DA QUALIDADE DE SEMENTES DE MILHO
}

\section{Pâmella Figueiredo Andolfi ${ }^{1}$ \\ Guilherme Luiz Pivatto ${ }^{2}$ \\ Gessane Abreu Olimpio ${ }^{3}$}

Resumo: Objetivou-se com esse trabalho avaliar a interferência do tempo de armazenamento no vigor de sementes de milho (Zea Mays L.). Para o estudo foram utilizadas sementes de milho da variedade BRAS 3010. Os tratamentos utilizados foram os seguintes: 3 amostras de milho da variedade BRAS 3010 compradas recentemente para o estudo; 3 amostras de milho da variedade BRAS 3010 com um ano de armazenamento sob refrigeração; e 3 amostras de milho da variedade BRAS 3010 com seis meses de armazenamento sob refrigeração. O teste foi realizado em rolo de papel umedecido em água destilada com 10 sementes. Após doze dias no germinador, as plântulas normais e anormais, foram contadas e medidas com auxílio de uma régua, com graduação em $\mathrm{cm}$. Observou-se que o vigor das sementes armazenadas por um ano foi comprometido. Conclui-se que o vigor obtido foi reduzido, devido a deterioração natural que as sementes apresentam ao serem armazenadas.

Palavras-chave: Qualidade; Germinação; Armazenamento; Zea mays L.

\footnotetext{
1 Agronomia/UFES, Brasil. E-mail: pamella_andolfi@hotmail.com.

2 Agronomia/UFES, Brasil. E-mail: pivatto.guilherme@gmail.com.

3 Agronomia/UFES, Brasil. E-mail: gessaneabreu@hotmail.com.
} 